\title{
Frequency of Covid Pneumonia and Trajectory of Severe Clinical Manifestations in Karachi
}

Fatima Jehangir, Zarish, Navaira, Aroosa Jehan, Tariq Adnan, Gul Sahib

Department of Family Medicine, Ziauddin University, Karachi, Pakistan.

\begin{abstract}
Background: Severe COVID-19 leads to acute respiratory distress syndrome (ARDS) and causes lung injury and covid Pneumonia. This lung injury is accompanied by a strong inflammatory response marked by very high levels of various cytokines in the serum. The objective of this study was to analyze the frequency of covid pneumonia in all affected patients and to observe the clinical cascade determining the poor prognostic markers.
\end{abstract}

Methods: This cross-sectional study selected 83 patients (>18 years) with reactive RT-PCR from April 2020 to March 2021. Non-reactive patients on RT-PCR but proven Covid 19 on HRCT, CO-RADS Category 5 and 6 were also included in the study. Clinical cascade was observed in week 1 and week 2 along with cytokine storm markers. Data were analyzed using SPSS version 20. The correlation was assessed through an independent t-test and $p$-value $<0.05$ was considered significant.

Results: Thirty-three (39.8\%) patients (mean age $47 \pm 17.2$ years), were found affected with covid pneumonia, among them, 12(14.5\%) died during the study. Most virus-contracted patients included highly educated people (83.1\%) and high-income individuals (61.4\%). Other than respiratory symptoms (72.3\%), Gl symptoms like diarrhea and vomiting $(59 \%)$ were also seen. Ferritin, D-Dimers, and LDH increased respectively $(353 \pm 340,16.5 \pm 60,265 \pm 273$ ) whereas CRP decreased $(57 \pm 69.3)$ in the second week.

Conclusion: Covid affects the pulmonary as well as extrapulmonary systems. Most patients remain asymptomatic, but hypoxic subjects showed an escalation in inflammatory markers such as CRP, Ferritin, and D-Dimers which declined the following week. High mortality was seen with those requiring ventilation $(p=0.000)$.

Keywords: Covid-19 Pneumonia; Pandemic; HRCT; RT-PCR.

\section{Corresponding Author: \\ Dr. Fatima Jehangir}

Department of Family Medicine,

Ziauddin University,

Karachi, Pakistan.

Email: fatima.jehangir@zu.edu.pk

https://doi.org/10.36283/PJMD11-1/007

How to cite: Jehangir F, Z, N, Jehan A, Adnan T, Sahib G. Frequency of Covid Pneumonia and Trajectory of Severe Clinical Manifestations in Karachi. 2022;11(1): 38-43. doi: 10.36283/PJMD1 1-1/007 


\section{INTRODUCTION}

Severe COVID-19 is associated with acute respiratory distress syndrome (ARDS). There have been observations of interstitial mononuclear inflammatory infiltrates with diffuse alveolar damage, hyaline membrane formation, and pulmonary edema in the lungs. The lung injury secondary to COVID-19 is accompanied by a strong inflammatory response marked by very high levels of various cytokines in the serum. Prognostic factors may help guide the stratification of patients with COVID-19 based on their risk of severe disease or death'. This risk stratification may help improve management and resource utilization strategies in the treatment of these patients. The study demonstrates that $39.8 \%$ of subjects developed COVID pneumonia, all of which were males. $14.5 \%$ of subjects died secondary to complications. Interestingly, none of the 30 female subjects involved in the study had developed COVID pneumonia ${ }^{1-2}$. These findings build on the existing evidence that there is an increased severity and mortality of COVID-19 in males. One study conducted in Wuhan Union Hospital illustrated that men were at greater risk of developing serious illness and the likelihood of being deceased from COVID-19 was 2.4 times higher as compared to women'.

Obesity is a known risk factor for COVID-19 severity and mortality due to various mechanisms that have been studied including chronic inflammatory state, reduced immune cell function, and lipotoxicity2. According to a study conducted in Shenzhen, China obese patients were 1.84 more likely to develop severe COVID-19 ${ }^{3}$. COVID-19 severity and smoking have been conflicting results but a meta-analysis on Chinese patients indicated that there is no significant association of smoking with increased risk of severe COVID-19 ${ }^{4}$. A more recent re-analysis found that smoking history was linked to the severity of COVID-19 and smokers are at greater risk for symptomatic COVID-19 ${ }^{5-7}$.

The spread of COVID is also more common in developed countries such as Europe and USA and mostly the privileged and the financially stable can afford expensive flights to these areas and risk being exposed to COVID-19 6. As a classist society, the upper class of people in Pakistan do not tend to mingle with the middle and lower class which could be why the spread is more common among them. Upperclassmen are also more likely to be obese or overweight as compared to the lower class. There could also be some discrepancy in our findings as to the underprivileged who are unable to afford COVID PCR testing or healthcare may go undiagnosed or may delay seeking care ${ }^{4,5}$. Regardless, this inequality and delay in care need to be addressed by governments. COVID PCR testing and healthcare should be free and more readily available for more accurate data on the matter. The objective of this study was to analyze the frequency of covid pneumonia in all affected patients and to observe the clinical cascade and determine the poor prognostic markers.

\section{METHODS}

A retrospective study was done on $n=83$ patients with reactive RT-PCR Covid-19 having age above 18 years. Those who were non-reactive on RT-PCR but proven Covid -19 on HRCT, CO-RADS Category 5 and 6 were also included in the study. Pregnant and lactating women were excluded. Covid-19 pneumonia was labeled to all HRCT proven subjects or on a definite consolidation on chest x-ray. The study was approved by an ethics review committee of Ziauddin University (Ref code 3330221FJFM). Informed consent was taken from all the patients. Patients were followed through house visits, tele-clinics, and on-site consultation in Clifton Consultant Clinic. Close follow-ups, daily to weekly were also taken after getting admitted in tertiary care hospitals, and outcome in case of mortality was documented as well. All clinical parameters were noted including fever, cough, extra pulmonary symptoms, chest auscultation as well as X-ray or HRCT findings. Weekly change including worsening or resolution of clinical condition, chest $x$-ray and cytokine storm markers such as CRP, Ferritin and D-Dimers were documented.

Data were analyzed using SPSS version 20. Correlation of age with categorical variables such as gender, covid induced pneumonia and mortality was assessed through an independent t-test. Mean and standard deviation was determined for numerical variables such as CRP, Ferritin, D-Dimers, LDH, $\mathrm{R} / \mathrm{R}$, temperature, SpO2 and heart rate and were compared in week 1 and 2 . Frequency and percentage were determined for categorical variables such as gender, income, smoking status, thrombocytopenia, fibrosis, obesity, and their impact on poor prognosis was assessed through cross-tabulation. $p$-value $<0.05$ was considered statistically significant.

\section{RESULTS}

The prevalence of covid pneumonia came out to be $39.8 \%$ (33) in this study. Table 1 demonstrates the variations in clinical manifestations and inflammatory bio-markers in week 1 vs week 2. Ferritin, D-Dimers and LDH rose whereas CRP declined in the second week. Table 2 shows the association of various factors with covid pneumonia and fibrotic lung disease. The mean age was $47 \pm 17.2$ years. Mostly highly educated people (83.1\%) and high-income individuals $(61.4 \%)$ contracted the virus. Other than respiratory symptoms (72.3\%), Gl symptoms like diarrhea and vomiting (59\%) were also seen. 
Table 1: Comparison of the clinical trajectory of inflammatory markers and physical exam findings.

\begin{tabular}{|c|c|c|c|c|}
\hline \multicolumn{5}{|c|}{ Inflammatory Markers } \\
\hline & CRP mg/l & Ferritin $\mathrm{ng} / \mathrm{ml}$ & D-Dimers mg/l & LDH \\
\hline Week 1 & $103.3 \pm 93$ & $248 \pm 284$ & $9.5 \pm 33$ & $150 \pm 45$ \\
\hline Week 2 & $57 \pm 69.3$ & $353 \pm 340$ & $16.5 \pm 60$ & $265 \pm 273$ \\
\hline \multicolumn{5}{|c|}{ Physical Examination Findings } \\
\hline & Respiratory Rate/m & Temperature C & SpO2 \% & Heart Rate/min \\
\hline Week 1 & $17.6 \pm 7.5$ & $37.9 \pm 0.94$ & $91 \pm 5.7$ & $86.1 \pm 19.7$ \\
\hline Week 2 & $20.5 \pm 8.1$ & $37.6 \pm 0.79$ & 90.8 & $79.6 \pm 24$ \\
\hline
\end{tabular}

Table 2: Association of lifestyle factors with pneumonia and fibrotic lung disease.

\begin{tabular}{|c|c|c|c|c|c|c|}
\hline Variables & $\begin{array}{c}\text { Pneumonia } \\
\begin{array}{c}\text { n (\%) } \\
N=33\end{array}\end{array}$ & $\begin{array}{c}\text { No } \\
\text { Pneumonia } \\
n(\%) \\
n=50\end{array}$ & $p$-Value & $\begin{array}{c}\text { Fibrosis } \\
\begin{array}{l}n(\%) \\
N=35\end{array}\end{array}$ & $\begin{array}{c}\text { No } \\
\text { Fibrosis } \\
n(\%) \\
n=48\end{array}$ & $p$-Value \\
\hline $\begin{array}{l}\text { Gender } \\
\text { Male } \\
\text { Female }\end{array}$ & $\begin{array}{c}33(100) \\
0(0)\end{array}$ & $\begin{array}{l}20(40) \\
30(60)\end{array}$ & 0.000 & $\begin{array}{c}32(91.4) \\
3(8.6)\end{array}$ & $\begin{array}{l}21(43.8) \\
27(56.2)\end{array}$ & 0.000 \\
\hline $\begin{array}{l}\text { Education } \\
\text { Graduation }\end{array}$ & $33(100)$ & $36(72)$ & 0.001 & $35(100)$ & $34(70.8)$ & 0.006 \\
\hline $\begin{array}{l}\text { Income in Rupees } \\
>1 \text { lac } \\
76 \mathrm{k}-1 \text { lac } \\
31-75 \text { lac } \\
<30 \mathrm{k}\end{array}$ & $\begin{array}{c}27(81.8) \\
5(15.2) \\
1(30) \\
0(0)\end{array}$ & $\begin{array}{c}24(48) \\
1(20) \\
19(38) \\
6(12)\end{array}$ & 0.000 & $\begin{array}{c}30(85.7) \\
5(14.3) \\
0(0) \\
0(0)\end{array}$ & $\begin{array}{c}21(43.8) \\
1(2.1) \\
20(41.7) \\
6(12.5)\end{array}$ & 0.000 \\
\hline $\begin{array}{l}\text { Coffee } \\
\text { Consumption } \\
\text { None } \\
1 \text { cup } \\
2 \text { cups } \\
>3 \text { cups }\end{array}$ & $\begin{array}{c}19(57.6) \\
10(30.3) \\
4(12.1) \\
0(0)\end{array}$ & $\begin{array}{c}2(4) \\
1(2) \\
26(52) \\
21(42)\end{array}$ & 0.000 & $\begin{array}{c}18(51.4) \\
10(28.6) \\
7(20) \\
0(0)\end{array}$ & $\begin{array}{c}3(6.2) \\
1(2.1) \\
23(47.9) \\
21(43.8)\end{array}$ & 0.000 \\
\hline $\begin{array}{l}\text { Sun exposure } \\
\text { none } \\
<1 \mathrm{hr} \\
1.1-2.9 \mathrm{hrs} \\
>3 \mathrm{hrs}\end{array}$ & $\begin{array}{c}25(75.8) \\
1(3) \\
6(18.2) \\
1(3)\end{array}$ & $\begin{array}{c}1(2) \\
0(0) \\
15(30) \\
34(68)\end{array}$ & 0.000 & $\begin{array}{c}21(71.4) \\
1(2.9) \\
5(14.3) \\
4(11.4)\end{array}$ & $\begin{array}{c}1(2.1) \\
0(0) \\
16(33.3) \\
31(64.6)\end{array}$ & 0.000 \\
\hline \multicolumn{7}{|c|}{ Correlation of age with mortality, gender, and pneumonia } \\
\hline Variables & \multicolumn{2}{|c|}{$X+S D$} & Upper & $\frac{\text { Cl }}{\text { Lower }}$ & \multicolumn{2}{|c|}{$p$-Value } \\
\hline Death & \multicolumn{2}{|c|}{$65.33+16.9$} & 11.69 & 31.07 & \multicolumn{2}{|c|}{0.000} \\
\hline Gender males & \multicolumn{2}{|c|}{$48.56+16.27$} & 12 & -3.6 & \multicolumn{2}{|c|}{0.286} \\
\hline Pneumonia & \multicolumn{2}{|c|}{$50.6+16.8$} & 13.5 & -1.7 & \multicolumn{2}{|c|}{0.126} \\
\hline
\end{tabular}


Figure 1 demonstrates prognostic markers such as $62.3 \%, 69.2 \%, 80 \%, 47.8 \%$ of subjects who had Pneumonia were male, smokers, obese and highly educated respectively. $52.9 \%$ of participants who had pneumonia were among the rich people. Post covid fibrosis was seen in $91.4 \%$ of cases of covid 19 pneumonia. Among all who had covid pneumonia, 27.8\% had thrombocytopenia, 33.3\% had thrombo- cytosis and out of subjects who did not have covid pneumonia, $72.2 \%$ had thrombocytopenia and $60 \%$ had thrombocytosis, results statistically significant (p-value 0.00) Statistically significant results were also seen with male gender, income $>$ Rs 1 lac and graduated individuals when cross-tabulated with covid pneumonia.

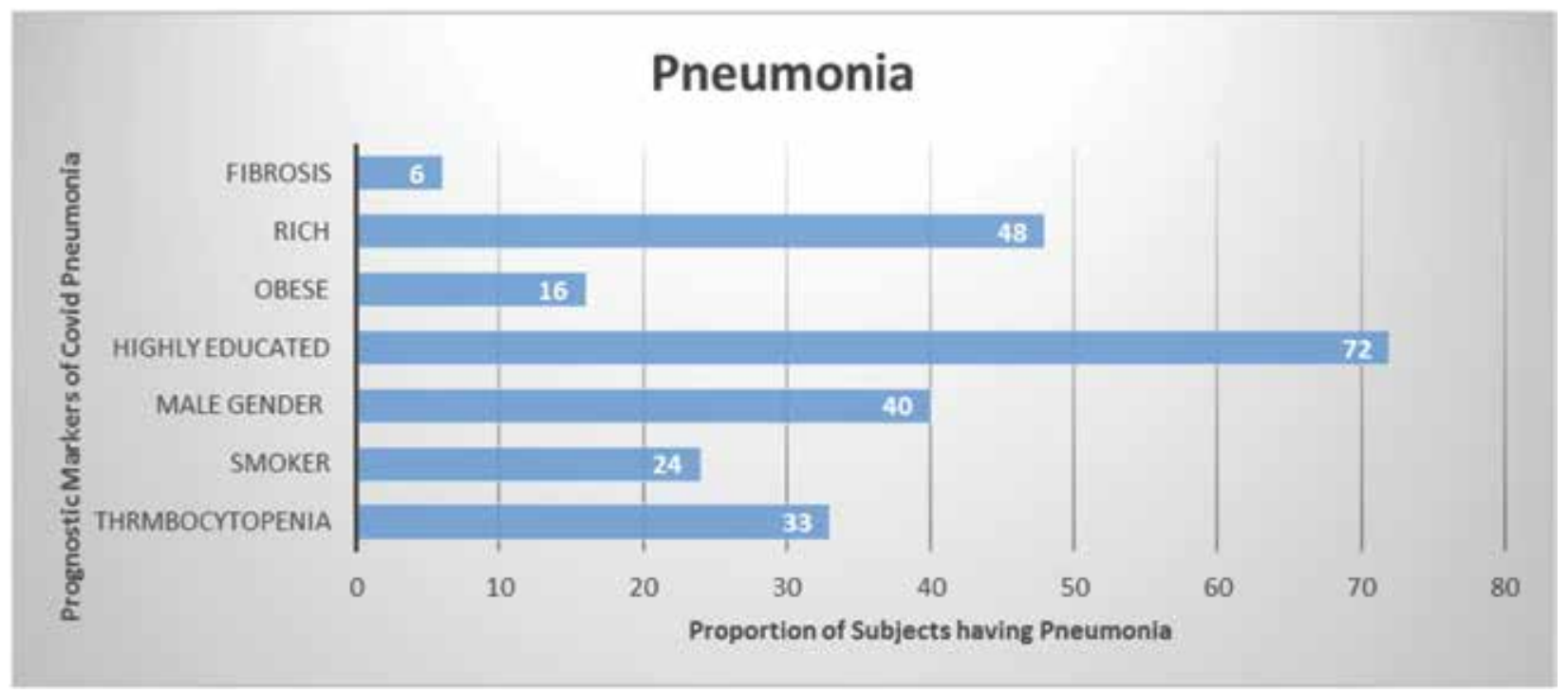

Figure 1: Prognostic markers of COVID-19 pneumonia.

Figure 1 demonstrates prognostic markers such as $62.3 \%, 69.2 \%, 80 \%, 47.8 \%$ of subjects who had Pneumonia were male, smokers, obese and highly educated respectively. $52.9 \%$ of participants who had pneumonia were among the rich people. Post covid fibrosis was seen in $91.4 \%$ of cases of covid 19 pneumonia. Among all who had covid pneumonia, $27.8 \%$ had thrombocytopenia, 33.3\% had thrombocytosis and out of subjects who did not have covid pneumonia, $72.2 \%$ had thrombocytopenia and $60 \%$ had thrombocytosis, results statistically significant (p-value 0.00) Statistically significant results were also seen with male gender, income $>$ Rs 1 lac and graduated individuals when cross-tabulated with covid pneumonia.

\section{DISCUSSION}

The current study displayed a strong correlation between obesity and COVID pneumonia. $80 \%$ of obese subjects developed pneumonia throughout their illness. Another correlation was found between smoking and COVID pneumonia reported that 69.2\% of smokers developed COVID pneumonia during the study. Post-COVID pulmonary fibrosis was seen in $91.4 \%$ of subjects who developed COVID pneumonia in this study. Previous literature has also shown evidence of pulmonary fibrosis following COVID-19 pneumonia. In one study COVID survivors developed impaired diffusion capacity and restrictive ventilatory defects at the time of discharge ${ }^{8}$.
In this study the link between thrombocytopenia and COVID pneumonia where $55 \%$ of subjects with thrombocytopenia developed COVID pneumonia. Another study in Wuhan, China also denoted a correlation between thrombocytopenia and increased mortality in COVID-19 patients with $72.7 \%$ of non-survivors developing thrombocytopenia ${ }^{10}$. Another meta-analysis of COVID-19 patients found that platelet count was decreased in patients with severe COVID-19 11,12. It was also observed in this study that there is a correlation between COVID-19 infection and status of wealth. Thus, $52.9 \%$ of subjects who developed COVID pneumonia were among the wealthy men and $47.8 \%$ were highly educated. COVID has been called the "disease of the rich". This correlation could be because upperclassmen tend to socialize in big gatherings as compared to middle and lower class ${ }^{13}$.

When we looked at the clinical manifestations, this study showed presentation with fever (65.1\%), dry cough (91.6\%), fatigue (100\%), myalgia (60.2\%), sore throat $(63.9 \%)$. Nausea, vomiting, and diarrhea were seen in $59 \%$ of people. It was seen that some patients may advance to shortness of breath in the second week of their illness which may be accompanied by or progress to hypoxemia ${ }^{14}$. A study conducted in Wuhan found that earlier in the course of the disease symptoms included cough 
(76\%), dyspnea (55\%), fever (98\%), myalgia or fatigue (44\%) and diarrhea (3\%). These studies show that the main clinical manifestations of Covid-19 are fever (90\% or more), cough (around $75 \%$ ) and dyspnea (up to 50\%). A small but significant subset has gastrointestinal symptoms ${ }^{15}$. Despite the percentage of patients having gastrointestinal symptoms being small, it is significant and more attention has been paid to it since a case was reported in the USA, where SARS-CoV-2 RNA was first detected in the stool'b.

On January 29, 2020 laboratory reports of 1099 confirmed COVID-19 patients from 522 hospitals in 30 provinces in China were collected to conduct the largest cohort study to date which concluded that digestive symptoms such as, diarrhea and nausea or vomiting were seen in $42(3.2 \%)$ and $55(5 \%)$ patients respectively ${ }^{17}$. Pan et al., described the clinical characteristics of COVID-19 patients with digestive symptoms in Hubei, China. This report showed that amidst the 204 covid positive patients, the chief complaint in 99 (48.5\%) patients was digestive symptoms. Those with $\mathrm{Gl}$ symptoms presented with a range of manifestations that included abdominal pain $(0.4 \%)$, vomiting $(0.8 \%)$, anorexia $(83.8 \%$ ) and diarrhea $(29.3 \%)^{18}$. There have been multiple studies that imply that SARS-CoV-2 can be transmitted by the feral-oral route because it can be detected in the stool of COVID-19 patients ${ }^{19,20}$. Keeping note of the fact that one of the biggest problems in Pakistan is poor hygiene, could explain why there was a high reporting incidence of patients with gastrointestinal issues. There are cases where despite a negative pharyngeal and sputum viral test, a positive fecal viral test has been reported ${ }^{21}$.

A few patients with COVID-19 may show vague neurological side effects, like confusion and headache ${ }^{22}$. Other clinical manifestations include anosmia $(57.8 \%)$ and ageusia (59\%). Approximately $15 \%$ $(15.3 \%, 488 / 3,191)$ of patients had ageusia or anosmia in the beginning phase of COVID-19. According to this study, ageusia or anosmia was essentially more common among females and younger individuals ${ }^{23}$. Also, another investigation in the US reported improvement at $74 \%$ of tainted patients, both olfactory and taste, that correlated with overall clinicalresolution ${ }^{24-25}$.

This study compared the clinical trajectory of patients in week 1 and week 2 and noted a significant rise in the levels of $L D H$, ferritin and d-dimers, while there was a conspicuous decline in the levels of C-reactive protein. While this study showed a drop in CRP levels, previous studies consistently show an increase in CRP levels in severely ill patients. In a study conducted in Beijing, CRP levels increased by $65 \%$ and were significantly higher in the group of severe patients in comparison with patients in the mild group ${ }^{26-28}$.

Specifically, the odds of the progression of hospital disease on admission were higher in not only high CRP and lower lymphocyte count but also old age. Furthermore, a study in COVID-19 patients of Wuhan suggested that one of the risk factors for the progression of the disease was CRP ${ }^{29}$. The rate of rising CRP values during the first seven days of hospitalization are good predictor of early ICU transfer. Furthermore, the correlation between CRP and LDH along with other inflammatory markers are suggestive of a connection between tissue damage, state of infection, and direct prompt hospitalization ${ }^{30}$.

\section{CONCLUSION}

Hypoxic subjects showed an escalation in inflammatory markers such as CRP, Ferritin and D-dimers which declined the following week. Medical comorbidities mainly led to deaths. As COVID-19 infection causes significant health threats like pneumonia, fibrosis, ARDS and mortality, early disease management is the key to boost cure rates hence prevent transmission and emergence of newer variants.

\section{ACKNOWLEDGMENTS}

The authors would like to thank the staff of the hospital for their support and cooperation.

\section{CONFLICT OF INTEREST}

There was no conflict of interest among the authors.

\section{ETHICS APPROVAL}

The ethics review committee of Ziauddin University approved this study (Ref code 3330221FJFM).

\section{AUTHOR'S CONTRIBUTION}

FJ and AJ were involved in conceiving the idea. Data acquisition, analysis and manuscript writing were done by FJ. AJ, Z, N, GS, and TA were involved in manuscript writing and proofreading.

\section{REFERENCES}

1. Jin JM, Bai P, He W, Wu F, Liu XF, Han DM, et al. Gender differences in patients with COVID-19: focus on severity and mortality. Front Public Health. 2020 29:8:1-6. doi: 10.3389/fpubh.2020.00152

2. Petrakis D, Margină D, Tsarouhas K, Tekos F, Stan $M$. Nikitovic $D$, et al. Obesity-a risk factor for increased COVID-19 prevalence, severity and lethality. Mol Med Rep. 2020;22(1):9-19. doi: 10.3892/mmr.2020.11127

3. Cai Q, Chen F, Wang T, Luo F, Liu X, Wu Q, et al. Obesity and COVID-19 severity in a designated hospital in Shenzhen, China. Diabetes Care. 2020;43(7):1392-1398. doi: 10.2337/dc20-0576

4. Lippi G, Henry BM. Active smoking is not associated with severity of coronavirus disease 2019 (COVID-19). Eur J Intern Med. 2020;75:107-108. doi: 
10.1016/j.ejim.2020.03.014

5. Farsalinos K, Bagos PG, Giannouchos T, Niaura R, Barbouni A, Poulas K. Smoking prevalence among hospitalized COVID-19 patients and its association with disease severity and mortality: an expanded re-analysis of a recent publication. Harm Reduct J. 2021;18(1):1-9. doi: 10.1 186/s12954-020-00437-5

6. Wang R, Pan M, Zhang X, Han M, Fan X, Zhao F, et al. Epidemiological and clinical features of 125 Hospitalized Patients with COVID-19 in Fuyang, Anhui, China. Int J Infect Dis. 2020;95:421-428. doi: 10.1016/j.ijid.2020.03.070

7. Hopkinson NS, Rossi N, El-Sayed_Moustafa J, Laverty AA, Quint JK, Freidin M, et al. Current smoking and COVID-19 risk: results from a population symptom app in over 2.4 million people. Thorax. 2021;76(7):714-722. doi: 10.1136/thoraxjnl-2020-216422

8. Mo X, Jian W, Su Z, Chen M, Peng H, Peng P, et al. Abnormal pulmonary function in COVID-19 patients at time of hospital discharge. Eur Respir J. 2020;55(6):1-4. doi: 10.1 183/13993003.01217-2020

9. Zhou S, Wang Y, Zhu T, Xia L. CT features of coronavirus disease 2019 (COVID-19) pneumonia in 62 patients in Wuhan, China. Am J Roentgenol. 2020;214(6):1287-1294. doi: 10.2214/AJR.20.22975

10. Lippi G, Plebani M, Henry BM. Thrombocytopenia is associated with severe coronavirus disease 2019 (COVID-19) infections: a meta-analysis. Clin Chim Acta. 2020;506:145-148. doi: 10.1016/j.cca.2020.03.022 11. Yang $X, Y$ ang $Q$, Wang $Y, W \cup Y, X \cup J, Y \cup Y$, et al. Thrombocytopenia and its association with mortality in patients with COVID-19. J Thromb Haemost. 2020; 18(6):1469-1472. doi: 10.1111/jth.14848

12. XU P, Zhou Q, XU J. Mechanism of thrombocytopenia in COVID-19 patients. Ann Hematol. 2020;99(6):1205-1208. doi: 10.1007/s00277-020- 0401 9-0

13. Gangemi S, Billeci L, Tonacci A. Rich at risk: socio-economic drivers of COVID-19 pandemic spread. Clin Mol Allergy. 2020;18(1):1-3. doi: 10.1186 /s12948-020-00127-4

14. Zhou M, Zhang X, QU J. Coronavirus disease 2019 (COVID-19): a clinical update. Front Med. 2020; 14(2):126-135.doi: 10.1007/s 1 1684-020-0767-8

15. Galanopoulos M, Gkeros F, Doukatas A, Karianakis G, Pontas C, Tsoukalas N, Viazis N, Liatsos C, Mantzaris GJ. COVID-19 pandemic: Pathophysiology and manifestations from the gastrointestinal tract. World J Gastroenterol. 2020; 26(31): 4579-4588. doi: 10.3748/wjg.v26.i31.4579

16. Holshue ML, DeBolt C, Lindquist S, Lofy KH, Wiesman J, Bruce H, et al. First Case of 2019 Novel Coronavirus in the United States. $N$ Engl J Med. 2019:929-936. doi: 10.1056/NEJMoa2001191.

17. Guan WJ, Ni ZY, Hu Y, Liang WH, OU CQ, He JX, et al. Clinical characteristics of coronavirus disease 2019 in China. N Engl J Med. 2020;382(18):1708-1720. doi: 10.1056/NEJMoa2002032
18. Pan L, Mu M, Yang $P$, Sun $Y$, Wang R, Yan J, et al. Clinical characteristics of COVID-19 patients with digestive symptoms in Hubei, China: a descriptive, cross-sectional, multicenter study. Am J Gastroenterol. 2020; 115 : 766-773. doi: 10.14309/ajg.0000000000000620

19. Yeo C, Kaushal S, Yeo D. Enteric involvement of coronaviruses: is faecal-oral transmission of SARS-CoV-2 possible? Lancet Gastroenterol Hepatol. 2020;5(4):335-337. doi: 10.1016/S2468-1253(20)30048-0 20. Wang W, XU Y, Gao R, LU R, Han K, Wu G, et al. Detection of SARS-CoV-2 in different types of clinical specimens. JAMA. 2020;323(18):1843-1844. doi:10.1001/jama.2020.3786

21. Chen L, Jianghua L, Bai Y, Wang M. COVID-19 disease with positive fecal and negative pharyngeal and sputum viral tests. Am J Gastroenterol. 2020; 1 15(5):790. doi:10.14309/ajg.0000000000000610

22. Mao L, Wang M, Chen S, He Q, Chang J, Hong $C$, et al. Neurological manifestations of hospitalized patients with COVID-19 in Wuhan, China: a retrospective case series study. MedRxiv. 2020:1-26. doi: 10.1101/2020.02.22.20026500

23. Lee $Y$, Min P, Lee S, Kim SW. Prevalence and duration of acute loss of smell or taste in COVID-19 patients. J Korean Med Sci. 2020;35(18):1-6. doi: 10.3346/jkms.2020.35.e174

24. Lechien JR, Chiesa-Estomba CM, De Siati DR, Horoi M, Le Bon SD, Rodriguez A, et al. Olfactory and gustatory dysfunctions as a clinical presentation of mild-to-moderate forms of the coronavirus disease (COVID-19): a multicenter European study. Eur Arch Otorhinolaryngol. 2020;277(8):2251-2261. doi: 10.10 07/s00405-020-05965-1

25. Zumla A, Hui DS, Azhar El, Memish ZA, Maeurer $M$. Reducing mortality from 2019-nCoV: host-directed therapies should be an option. Lancet. 2020;395(10224) :35-36. doi: 10.1016/S0140-6736(20)3 0305-6

26. Liu F, Li L, Xu M, Wu J, Luo D, Zhu Y, et al. Prognostic value of interleukin-6, C-reactive protein, and procalcitonin in patients with COVID-19. J Clin Virol. 2020;127:1-5. doi: 10.1016/j.jcv.2020.104370

27. Pepys MB, Hirschfield GM. C-reactive protein: a critical update. J Clin Invest. 2003;111(12):1805-1812. doi: 10.1172/JCl18921

28. Sahu BR, Kampa RK, Padhi A, Panda AK. C-reactive protein: a promising biomarker for poor prognosis in COVID-19 infection. Clin Chim Acta. 2020;509:91-94. doi: 10.1016/j.cca.2020.06.013

29. Hou W, Zhang W, Jin R, Liang $L, X \cup B, H \cup$ Z. Risk factors for disease progression in hospitalized patients with COVID-19: a retrospective cohort study. Infect Dis. 2020;52(7):498-505. doi: 10.1080/23744235.2020.17 59817

30. Poggiali E, Zaino D, Immovilli P, Rovero L, Losi G, Dacrema $A$, et al. Lactate dehydrogenase and C-reactive protein as predictors of respiratory failure in CoVID-19 patients. Clin Chim Acta. 2020;509:135-138. doi: 10.1016/j.cca.2020.06.012 